\title{
Research on the Thought to Reform the Teaching Mode of Fine Arts Course at Colleges and Universities
}

\author{
Liu Xiaofei \\ School of Arts, Xi'an University, Shaanxi, China, 710065 \\ Keywords: Colleges and Universities; Fine Arts Course; Teaching; Reform \\ Abstract: After many years of development, the Fine Arts course teaching in China's \\ colleges and universities has achieved remarkable results in many aspects. However, with \\ the development of the times and the social progress, the teaching of Fine Arts course in \\ colleges and universities has been unable to meet the needs of modernization in many \\ aspects. How to do a good job to reform the teaching of Fine Arts course at colleges and \\ universities in the new era is not only the need of the development of colleges and \\ universities but also the inherent need of the development of Fine Arts course.
}

\begin{abstract}
Although the teaching of the Fine Arts course at colleges and universities started late in China's educational system, after years of continuous development, remarkable achievements have been made in many aspects, especially in the construction of curriculum system and personnel training. However, with the development of the society and the evolution of the times, some factors in the teaching of Fine Arts course at colleges and universities are unable to fully adapt to the requirements of the country for the cultivation of talents and the needs of discipline construction. Particularly, in the context of market economy and quality-oriented education, education reform has gradually entered the stage of intensive reform, and all colleges and universities are actively exploring reform models suitable for the long-term development of the university and the discipline. Of course, the Fine Arts course at colleges and universities cannot remain unchanged. How to adapt to the tide of the times and explore the high-level fine arts talent training mode that suits the discipline and meets the needs of social development is an era subject for every fine arts educator at colleges and universities.
\end{abstract}

\section{Problems in the Teaching of Fine Arts Course at Colleges and Universities}

The problems in the teaching of Fine Arts course at colleges and universities in China can be summarized as follows:

\subsection{The concept lags behind.}

Fine Arts is a more comprehensive form of art, and fine arts education should cover many aspects. The correct concept of fine arts education should be inclusive, which is in line with both the diverse and comprehensive characteristics of fine arts and the development trend of fine arts education. We can't regard Fine Arts as a singular skill-based training. Many teachers have a great 
understanding in this regard. They think that the fine arts knowledge and skills in fine arts education are at the core of the whole education system, and they often neglect the cultivation of students' independent learning ability and self-creation. The art without individuality and innovation will decay sooner or later.

\subsection{The teaching methods are obsolete}

As the main front for the cultivation of talents in China, colleges and universities should be the most advanced positions for accepting new ideas and new technologies. However, throughout the teaching of various disciplines at China's colleges and universities, in many respects and the frontiers, the teaching is by no means at the frontline. Especially, in terms of the teaching methods, many college teachers still follow the rigid and monotonous teaching mode. The teacher is the center of the whole class during the class, and the students are in a passive acceptance position. There is very little interaction between students and the teachers at class. The teacher blindly instills and teaches the theoretical knowledge through explanation. This blunt teaching method has seriously hindered the healthy development of various disciplines. Fine Arts course is a very practical course. The traditional teaching method can hardly achieve the teaching expectations in effect, and it is also difficult to stimulate students' interest in learning. In some respects, it even limits the self-ability of students. Regrettably, this kind of teaching method is not rare in the teaching of various subjects at Chinese universities.

\subsection{Teachers' overall quality is not high}

What is a good fine arts teacher like? If this question cannot be answered positively, let us first discuss the meaning of fine arts. Fine Arts is an art form that originates from life but is higher than life. The fine arts works should be the conciseness of life. We must feel something about the appreciation of the fine arts works. This proves from one side that fine arts is not just a skill, but it is a combination of various components of life. Therefore, Fine Arts is rich in content. It is not an isolated existence, but it is connected with many disciplines and it can be integrated. Therefore, a qualified Fine Arts teacher must not only master the knowledge and skills of Fine Arts, and at least a good Fine Arts teacher should understand the basic skills of education and teaching. The fine arts teachers in colleges and universities in China generally graduate from the professional fine arts college. One of the drawbacks of the professional fine arts college in enrollment is that they only pay attention to students' current fine arts skills and fine arts works, but they ignore students' comprehensive ability. Fine arts colleges' comprehensive enrollment score is significantly lower than that of other colleges, which leads to the low comprehensive ability of students. Many of the fine arts teachers at colleges and universities have obvious shortcomings, which greatly restricts their own future development and affects the development of education and teaching in many regards. The problems in the teaching of fine arts at colleges and universities have attracted the attention of many scholars. Especially, the lack of humanistic spirit training in the teaching of fine art courses is not a simple education and teaching problem, but more a social problem.

\subsection{The assessment system is not systematic}

The Fine Arts course assessment system at Chinese colleges and universities is not tailor-made for the fine arts students, but it follows the traditional test-taking assessment and serves the exam-oriented education. Such an assessment system is neither reasonable nor scientific, and it has been widely criticized. This assessment mode has a very negative impact on students' fine arts learning, and it is easy for students to simplify the purpose of fine arts learning. The traditional 
assessment system is currently the most widely used in the assessment of art students, and it should be broken the most urgently.

\section{Principles of Reforming Fine Arts Course}

The reform of teachings Fine Arts course teaching at colleges and universities is a systematic, comprehensive system, which takes its lead. In a certain sense, the success or failure in the reform of the teaching of Fine Arts course at colleges and universities is not only related to the success or failure of training higher-level fine arts talents' ability but also affects the overall education and teaching reform process of the university. The teaching reform of the Fine Arts course at colleges and universities must be oriented at talent cultivation. In short, it is to take reform as a driving force, effectively improve students' ability to learn fine arts and their practical skills of fine arts and stimulate students' learning potential. The competition between countries today is, in the final analysis, the competition of talents and the competition of talent cultivation ability. In the reform of teaching Fine Arts course at colleges and universities, we should focus on improving students' comprehensive quality and innovative ability and strive to align with the international advanced education and teaching achievements. We must adhere to the educational philosophy of applying what we have learned, transform what we have learned into what we use, use what we have learned, and improve our students' ability to use knowledge.

The Fine Arts course at colleges and universities has its own characteristics. After years of development of the Fine Arts course at China's colleges and universities, the disadvantages of many places have reached a point where it has to be changed. However, this process should be carried out step by step and should not be reformed for reform, trying to achieve the desired goal through a one-step process. This is a kind of quick success and unrealistic performance in education and teaching. In the reform, we must do a good job in the preliminary research, gathering wisdom and accumulating efforts to achieve a smooth transition.

\section{The Content of Reforming the Teaching of Fine Arts Course at Colleges and Universities}

To do a good job in reforming the teaching of the Fine Arts course at colleges and universities, we should focus on the following aspects:

\subsection{Establish a new concept of education and teaching}

We must always view the problem from the perspective of development. First of all, we must clear the shackles of the traditional concept of fine arts from the perspective of thinking, and correctly and comprehensively consider the reform of Fine Arts course. In the context of quality-oriented education, we must integrate the concept of improving students' comprehensive ability into daily education and teaching, instead of letting it stay on the slogan. To this end, the majority of educators must be good at learning, innovation as well as finding and solving problems. Breaking the problem of its own existence is the foundation and the key. We must take the requirements of the times and future development as the basis of education and teaching, fully recognize the current situation and direction of education reform, and we should not be self-sufficient and act blindly. Instead, we should be good at referring to the advanced concepts of others and be brave enough to apply these advanced concepts to education and teaching.32.2 Establish a scientific concept of art for students

The fundamental purpose of education is to guide students through education and teaching. According to the characteristics and reality of each student, we should systematically guide and train students to realize and improve their own value. Art can influence personalities in this regard. 
However, the current fine arts teaching at many colleges and universities has obvious attributes of quick success and instant benefit. Some people even use secular values as the orientation of talent cultivation and try to consider the value of teaching through the commodification and value of spiritual products. There are also so-called artists who are blindly pursuing unconventionality and even seeks hotspots through some boring and empty art forms and means in a bid to find their own value in the attention of everyone. An important aspect of China's fine arts teaching reform is to guide the students to establish a scientific artistic view, so that they have the basic ability to distinguish and the right and wrong. Art needs innovation, but innovation is by no means unreasonable.

\subsection{Focus on cultivating students' humanistic spirit}

From a certain perspective, the humanistic spirit is a manifestation of cultural thoughts and a kind of people's pursuit of quality life. Paying attention to the cultivation of humanistic spirit in the teaching of fine arts can effectively improve students' cultural, moral and emotional qualities, and it plays a significant role in promoting the improvement of students' comprehensive ability and the development of their physical and mental health. At present, there are many vain phenomena in the teaching of fine arts at colleges and universities in China, which are directly related to the lack of God in the teaching of fine arts. The humanistic spirit is an ideological attitude. It not only pays attention to the ideological problems that arise in human existence but also emphasizes the free and peaceful relationship between man and nature and between people. The humanistic spirit also attaches great importance to the shaping of human personality and ideals and beliefs. The core of the humanistic spirit is the creativity of art. At present, the mode and environment of fine arts teaching in colleges and universities in China are relatively fixed and closed, which limits the cultivation of students' diversified ideas to a certain extent. Therefore, in education and teaching, we should try our best to strengthen the cultivation of students' humanistic spirit, enhance students' diversified innovation, realize the dual improvement of students' aesthetic quality and artistic cultivation, and promote the coordinated development of students' mind and body. Fine Arts has a unique humanistic color and humanistic connotation. The theory of fine arts teaching, aesthetics itself belongs to the category of culture.

\subsection{Pay attention to the application of scientific teaching methods in education}

Nowadays, with the rapid development of science and technology, teachers shoulder a special historical mission in cultivating students' innovative spirit. To cultivate students' innovative spirit, teachers themselves must be good at innovation. If teachers lack innovative thinking, then the discipline will lose its soul and motivation. The application of new media technology in education and teaching includes many cutting-edge scientific and technological achievements. To some extent, the Fine Arts course in the new media environment is a new concept course. It is based on information technology and network technology and extends to various fields such as communication and multimedia. If teachers want to fully adapt to the teaching with the new media, they must integrate and improve their knowledge structure and broaden their horizons. This process is a process of self-improvement and self-remodeling of the majority of fine arts teachers, and it is also a process of enhancing teachers' self-innovation ability. This will deeply affect the understanding of the fine arts teachers in the new media environment at the intellectual level. This is both an extension of ideological understanding and an experience of practical action. The use of new media can effectively improve the display and interaction of teaching methods in the process of teaching complex knowledge, resulting in explosive growth of teaching content and teaching capacity. In the new media environment, fine arts teachers at colleges and universities can use 
modern technologies to produce high-quality courseware with rich content, various forms and close to students' preferences. The communication between students and teachers is no longer limited to time and space, communication can be carried out anytime and anywhere. The teachers' teaching is no longer as rigid as in the past, but teachers can forward pictures, texts, sounds, images and other information from time to time by means of computers, projectors, network terminals and other tools. In the new media environment, the college Fine Arts course has undergone tremendous changes in terms of information transfer structure, students' understanding structure, classroom time integration, and teacher-student communication methods. Rich and interesting teaching methods and teaching contents have greatly stimulated students' interest in learning and led students to explore unknown areas. In the new media environment, knowledge is no longer a boring symbol but becomes a living individual. All-round stimulation of students' cognition and understanding of English can effectively improve students' learning efficiency and memory, thus fully optimizing classroom efficiency and improving teaching quality.

\subsection{Focus on cultivating students' practical ability}

The Fine Arts course teaching in higher education in China pays more attention to students' practical ability from the initiation, but the practical environment we have provided for students has not changed much. In the new historical period, China's investment in fine arts education has increased year by year. Each school and the fine arts department should provide a good practical environment for the students according to their own characteristics and conditions of education and teaching. And they should try to let students move and go out, understand and digest the knowledge in practice to strengthen their mastery of knowledge.

\section{References}

[1] Xin Dongwa. Details[m]. Beijing: Peking University Press, 2010.

[2] Hu Jihua. The Aesthetic Dimension of Chinese Cultural Spirit [m]. Beijing: Peking University Press, 2009.

[3] Feng Minsheng. A Comparative Study of the Spatial Expressions of Traditional Chinese and Western Paintings [m].

Beijing: China Social Sciences Press, 2007.

[4] Bu Su. Fine Arts Education and Ability Training at Colleges and Universities [J]. Journal of Puyag Vocational and Technical College, 2008(30).

[5] Lu Jing. Cultivation of Humanistic Spirit in the Teaching of Fine Arts in Normal Colleges [J]. Neijiang Technology, 2007(09).

[6] Zhang Wen. On the Importance of Sensual Training in the Teaching of Fine Arts at Colleges and Universities [J]. Young Literature Writer, 2011(11). 